\title{
Case Report: The Effect of Virtual Reality Practice on Postural Control and Balance in Children With Cerebral Palsy: A Single-Subject Study
}

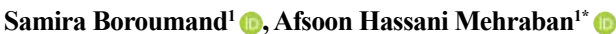

1. Department of Occupational Therapy, School of Rehabilitation Sciences, Iran University of Medical Sciences, Tehran, Iran.

\begin{tabular}{|c|c|}
\hline $\begin{array}{l}\text { Use your device to scan } \\
\text { and read the article online }\end{array}$ & Cht Brand S. Hassani Mehraban A. The Effect of Virtual Reality Practice on Postural Control and Balance in \\
\hline 口ifip & $\begin{array}{l}\text { Children With Cerebral Palsy: A Single-Subject Study. Iranian Rehabilitation Journal. 2018; 16(4):413-424. http://dx.doi. } \\
\text { org/10.32598/irj.16.4.413 }\end{array}$ \\
\hline 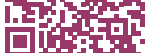 & doi' http://dx.doi.org/10.32598/irj.16.4.413 \\
\hline
\end{tabular}

Article info:

Received: 26 Jun 2018

Accepted: 13 Oct 2018

Available Online: 01 Dec 2018

Keywords:

Virtual reality, Postural balance, Weight shift, Cerebral palsy, Hemipleg

\section{ABSTRACT}

Objectives: Virtual reality is a new technology that has been recently used for different purposes in the rehabilitation of children. This study aimed to investigate the effectiveness of this method in balance rehabilitation of children with Cerebral Palsy (CP).

Methods: This was an A-B-A design single subject study in which 3 children with hemiplegic $\mathrm{CP}$ participated. The baseline phase and intervention phase, lasted 2 and 4 weeks, respectively. Then, the secondary evaluation phase was held at an evaluation session. Intervention sessions as the baseline phase were repeated 3 times a week. In each session, children performed different computer games with displacement of the center of pressure in frontal and sagittal planes (for $21 \mathrm{~min}$ ). The secondary evaluation phase of this study was held 2 to 3 months after the completion of the intervention phase. The changes made in this study were evaluated by assessment tools of Pediatric Reach Test (PRT), Single Limb Stance (SLS), Plate sensitive to pressure of Biometrics Ltd E-LINK force plate, and Activity Scale for Kids (ASK). Finally, the results were evaluated by $\mathrm{C}$ static and the visual analysis method.

Results: Comparison of the results of PRT, ASK and the evaluation of planes sensitive to pressure of Biometrics Ltd E-LINK in all 3 phases revealed the significant improvement of dynamic balance and the enhancement of the independence performance of children in daily living activities and the sustainability of the recovery in the secondary evaluation phase. Although, the SLS test results and data of force Plate indicated no significant improvements in the static balance of patients.

Discussion: The study results suggest that weight shift exercises with the use of virtual reality can effectively improve the dynamic balance of children with CP. However, it fails to make a significant change in the static balance of these children.

\section{* Corresponding Author:}

Afsoon Hassani Mehraban, PhD.

Address: Department of Occupational Therapy, School of Rehabilitation Sciences, Iran University of Medical Sciences, Tehran, Iran

Tel: +98 (918) 7561303

E-mail: afsoonmehraban@hotmail.com 


\section{Highlights}

- Weight shift practice with the use of virtual reality can significantly improve dynamic balance in hemiplegic cerebral palsy children, but not their static balance.

- Improving dynamic balance practice may not be extended to static balance.

\section{Plain Language Summary}

One of the most common problems in hemiplegic cerebral palsy children is postural control and balance. This problem produces a lot of disability in activities of daily living and play and has adverse effect on their self-confidence. Thus, one of the important objectives for family and therapist in rehabilitation center is improving balance and postural control of these children. On the other hand, most of the family members and even therapists complain about low children's desire for doing practice. However, many children are interested in performing video games. Therefore, we investigated the effect of virtual reality practice (weight shift practice on affected limb) on postural control and balance of hemiplegic cerebral palsy children.

In this research, 3 hemiplegic children participated in 12 virtual reality game treatment sessions. Changes in balance and postural control of these children showed the positive effect of virtual reality practice on improving dynamic balance, but not static balance. So we can say that using virtual reality practice in rehabilitation clinics is useful method to improve dynamic balance. Change in balance and postural control was observed using Pediatric Reach Test, Single Limb Stance, plates sensitive to pressure of Biometrics Ltd E-LINK and force plates shows positive effect of Virtual reality practice on improving dynamic balance, but this result shows that this practice cannot improve static balance. So we can say that using virtual reality practice in rehabilitation clinics is useful method to improve dynamic balance.

\section{Introduction}

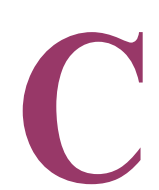

erebral Palsy (CP) is the most common cause of physical disability in early childhood [1]. Meanwhile, hemiplegia is the most frequent type of $\mathrm{CP}$ among preterm infants. It is the second type of $\mathrm{CP}$ among preterm infants [2] and constitutes $33 \%$ of children with CP [3]. Children with hemiplegia experience various impairments including spasticity, paralysis, and muscle weakness in the half of the body because of involvement of the cerebral hemisphere [4].

Studies indicate that patients with hemiplegia have higher weight on the healthy limbs when standing because of cerebral hemisphere involvement. Putting more weight on certain limbs directs the center of pressure on the healthy limb [5]. More use of healthy limb causes reduction of bone density and shortness of the involved limb, as well as exposure to instability and frequent falls [6]. These children usually survive until adulthood. Thus, frequent falls may cause damage and reduce their selfconfidence and consequently their participation in social, family, and working activities decrease [7]. Therefore, a constant goal in the rehabilitation of children with hemiplegia is encouraging them to displace the center of pressure onto the affected limb and build-up symmetry in weight bearing on both lower extremities in standing position, thus contributing to balance improvement [8].

Conventional treatments used to improve children's balance mainly focus on performing single-leg or double-leg activities on fixed or mobile surfaces, and ultimately adding these exercises to other tasks. Although these treatments are effective, they are often boring and exhausting [9]. According to Shumway, motivation is among basic elements in motor learning [10]. However in most disorders, rehabilitation takes a long time and creating and preserving a stimulating and exciting therapeutic environment is a difficult task and a constant challenge for pediatric therapists [11]. In this regard, virtual reality as a new tool provides a promising perspective for rehabilitation, and it seems that it addresses this challenge to some extent [12].

Virtual reality is a computer technology, which simulates virtual environment similar to the real environment, using computer software and hardware. This environment allows disabled people to communicate with the represented images and movements of virtual objects [13]. In such technology, individuals are able to perform activities that are impossible for them in real world with a perfect security level [14]. Virtual reality can create an opportunity for complete participation in pleasant, pur- 
poseful, and meaningful tasks related to real life for the individuals [15].

Many studies have investigated the impact of exercises in virtual reality on balance and postural control in adult neurological patients [16-18]. However, a few number of them studied the impact of this technology on children balance, and especially in children with CP. Reid (2002) first investigated the impact of implementing exercises using virtual reality on the improvement of postural control in patients with CP in the sitting position, and gained positive changes [19]. These changes were such that he proposed implementing exercises using virtual reality as part of the process of occupational therapy for children with CP. After that, separate studies by Deutsch [14] and Tatla [20] in 2008 and 2012, respectively, indicated the positive impact of implementing balance exercises in virtual reality on the improvement of balance and postural control of children with CP in standing position.

The study by Silva (2015) also revealed the positive impact of rehabilitation exercises using virtual reality on balance of a child with ataxic $\mathrm{CP}$ and introduced virtual reality as a suitable tool for balance rehabilitation in children with CP [21]. In addition, he mentioned few studies in this regard, and the need for more studies. Considering a few studies in this area, Cho investigated the impact of implementation of treadmill exercises using virtual reality on the balance of children with CP. Cho demonstrated the positive impact of using virtual reality on improving balance and power of children with $\mathrm{CP}$ [22].

Considering these findings and a few number of studies with long-term follow-up periods, current research aimed to investigate the impact of implementing rehabilitation exercises, using virtual reality, on the static balance and postural control of children with hemiplegic $\mathrm{CP}$ and its lasting potential effects.

\section{Methods}

\section{Research type}

This was a single-subject research (A-B-A type). It was conducted in 2014 in the Rehabilitation Faculty of the same university. Single-subject studies are often used in the investigation of new subjects or rare cases. Low number of participants and repeated evaluations are the main characteristics of this type of studies that allow an accurate examination of changes in every patient. A-B-A single-subject study type records basic abilities of the patients at initial evaluation phase. Accordingly, it allows the investigation of treatment impact in inter- vention phase. Also, with the elimination of treatment in secondary evaluation phase, it allows the investigation of treatment stability and its impact [23]. In this study, primary evaluation phase lasted almost 2 weeks, treatment phase lasted 4 weeks, and follow-up phase was run in an evaluation session, approximately 2-3 months after the completion of the treatment.

\section{Study participants}

Three hemiplegic CP children with GMFCS (Gross Motor Function Classification System) level I participated in the current research. Inclusion criteria were being diagnosed with hemiplegic CP based on a physician's report or review of medical records, age range of 7 to 12 years, normal intelligence (studying in normal schools), having a $90^{\circ}$ angle of the ankle in standing position and having enough satisfaction and motivation to participate in the research project. The exclusion criteria included drug-resistant seizures, ability to stand on one leg for more than 10 seconds, the presence of visual and auditory defects irreparable with the help of auxiliary equipment, and the lack of cooperation with the therapist during exercises and tests. Based on these criteria, three children with CP Mean \pm SD age: $10.37 \pm 2.93$ years were selected to participate in the study. Their characteristics are presented in Table 1

\section{Study procedure}

Current study was run at 3 phases as follows: primary evaluation or baseline phase (A), intervention phase (B), and secondary evaluation or follow-up phase (A). Primary evaluation phase consisted of 4 sessions with 3 repetitions per week. The Pediatric Reach Test (PRT), Single Limb Stance (SLS), Activities Scale for Kids (ASK), and Biometrics Ltd E-LINK (the evaluation of maximal weight shift on the affected limb in the sagittal and frontal plane with open and closed eyes and evaluating deviation from the center in a standing position with open eyes for 30 seconds), were used. In addition, the center of pressure was examined to measure participants' abilities. Data collection of the center of pressure in this study was performed in a standing position with open and closed eyes, with a frequency of $100 \mathrm{~Hz}$ and sampling time of 30 seconds. PRT and Biometrics Ltd E-LINK data were reviewed at each primary evaluation session. However, SLS, ASK, and the center of pressure tests were only examined at the end of the primary evaluation phase.

At the end of primary evaluation phase, treatment phase was immediately started. This phase lasted for 1 
month. Similar to primary evaluation phase, it was run 3 times per week. At the end of each treatment session, after the implementation of computer games, PRT and Biometrics Ltd E-LINK data were measured. In addition, two tests were used to assess the patient's abilities in the $6^{\text {th }}$ and $12^{\text {th }}$ sessions of the treatment phase by SLS, ASK and the examination of fluctuations of center of pressure with open and closed eyes, on the force plate. In 2-3 months after the last treatment session, follow-up or secondary evaluation phase was held, and the probable duration of treatment effects was evaluated in an assessment session using all of the tests mentioned in the primary evaluation phase. Duration for follow-up phase for each patient is presented in Table 1.

The number of primary evaluation phase sessions in this research was specified considering ethical issues and paying attention to the results of the pilot study, which was conducted with participation of a 4.5-5 year-old child with CP.

\section{Research tools}

PRT: It is a simple, reliable, and valid test for investigating the balance of children in standing and sitting positions on stool. The distance the child can reach forward and the sides without losing his balance and lifting the heel or shaking the foot, then return to his/her initial state is recorded, for investigating balance [24].

SLS: It is a simple, quick, reliable, and valid test for investigating static balance in children with CP. In this test, static balance is investigated by the calculation of period that one can stand on one leg with hands on the waist $[25,26]$.

ASK: It is an appropriate questionnaire for investigating independent performance in children (5-15 years old) with musculoskeletal disorders in the daily activities. It measures child's performance level in a specific period. Thus, it allows the measurement of changes over time. According to studies by Dehghan et al. this test has high reliability and validity among the Iranian children with CP [27].

Biometrics Ltd E-LINK: It is a computer system with the capability of implementing multiple assessments and medical exercises in the form of defined games. This tool was designed in England aiming to be used in rehabilitation clinics. The lower extremities set of this system (EP40 Dual-axis Force Plate System), includes a 24-inch screen and 4 sensitive 14 -inch thick $200-\mathrm{mm}$ screens that are connected by a cable to a central machine. The de- vice software enables therapist to record the fluctuations of weight distribution in the standing position and the amount of voluntary force imposed to each lower limb [28]. In this research, the Biometrics Ltd E-LINK was used for the assessment and implementation of virtual reality practice.

Force Plane Device: It is a suitable and accurate tool for recording the center of pressure data, which allows detecting the smallest changes in postural control [29]. In this study, Kistler Force Plane, Model 2260A, in Rehabilitation Faculty of Iran University of Medical Sciences was used for recording the center of pressure data.

\section{Intervention process}

All 3 participants attended 12 treatment sessions with 3 repetitions per week. Every treatment session consisted of the implementation of computer games in Biometrics Ltd E-LINK for 21 minutes, and performing specified tests. The games applied in this study were selected according to the treatment goal and based on the results of the pilot study. The games were performed with the displacement of center of pressure in both sagittal and frontal axes in standing position and could be defined either in a single axis or dual axes by the device.

At each session, the patients initially performed 16min single axis games that required shift of the weight in the frontal (driving, football, basketball) and sagittal axis (monkey, skating and shooting in space). Then, they played two-axis games (golf, puzzles, and the selection of uniform shapes), for 5 minutes. At the end of each session and following finishing the computer games, the changes of children in balance skills and weight shifting on the affected limb were measured using the mentioned tests. In the next session, depending on the progress and ability of the child, the levels of game got more difficult by increasing weight shifting on the affected limb and increasing the speed of game. During the research, whenever the child got tired, the treatment process was stopped, and it was continued after the elimination of exhaustion.

\section{Statistical analysis}

Firstly, serial dependence among all obtained data was investigated using Excel 2016. Following the absence of significance in data dependence (Table 2), visual analysis, 2SD method, and C Static were used for measuring the significance of changes in the specified tests. If the results of Pearson correlation coefficient for the data with series dependency classified based on time order were not significant, variance analysis, t-test or Mann-Whitney U 
Table 1. Clinical characteristics of the study participants

\begin{tabular}{ccccc}
\hline Participant & Age & Gender & Hemiplegic Side & Follow-Up Duration \\
\hline 1 & 12 years and 3 months & Female & Right & 9 weeks \\
2 & 11 years and 8 months & Male & Left & 11 weeks \\
3 & 7 years & Male & Right & 11 weeks \\
\hline
\end{tabular}

Iranian Rehabilitation Journal

test could be used for statistical investigation [30]. Data of force plate device were analyzed using 2-way Analysis of Variance (ANOVA) and considering the patient as random-effects (repeated measures) in SPSS.

\section{Results}

All participants passed all research steps without any physical damage or fall. Statistical tests were performed using the 2SD method and the C Static at the significance level of $\mathrm{P}<0.05$. Test results demonstrated a stable pattern in the baseline phase of all subjects. Biometrics Ltd E-LINK data analysis on maximum weight shift in the affected limb, in frontal and sagittal planes with open and closed eyes were performed using $\mathrm{C}$ Static, visual analysis and 2SD method. The obtained data revealed significant statistical changes from the base phase to the treatment phase. The prolonged stability of these changes in the secondary evaluation phase was confirmed, too. According to 2SD statistical test, data stability was not significant in maximum weight shift on the affected limb in the frontal plane with the open eyes in the first patient. Also, the maximum weight shift to the back in the sagittal plane with the open eyes in the second patient, and maximum weight shift in the frontal plane with the closed eyes in the third patient (Figures 1, 2, and 3, Table 3) were not significant.

Table 2. Serial dependency results

\begin{tabular}{|c|c|c|c|}
\hline Variable & Participant & Autocorrelation & Interpretation \\
\hline \multirow{3}{*}{$\begin{array}{l}\text { Weight shift in sagittal plane with open eyes } \\
\text { (to the front-injury side) }\end{array}$} & 1 & 0.063 & Not significant \\
\hline & 2 & 0.277 & Not significant \\
\hline & 3 & 0.166 & Not significant \\
\hline \multirow{3}{*}{$\begin{array}{l}\text { Weight shift in frontal plane with open eyes } \\
\text { (to the injury side ) }\end{array}$} & 1 & 0.236 & Not significant \\
\hline & 2 & 0.5 & Not significant \\
\hline & 3 & 0.007 & Not significant \\
\hline \multirow{3}{*}{$\begin{array}{l}\text { Weight shift in sagittal plane with open eyes } \\
\text { (to the back-injury side) }\end{array}$} & 1 & 0.07 & Not significant \\
\hline & 2 & 0.35 & Not significant \\
\hline & 3 & 0.096 & Not significant \\
\hline \multirow{3}{*}{$\begin{array}{l}\text { Weight shift in frontal plane with closed eyes } \\
\text { (to the injury side ) }\end{array}$} & 1 & 0.073 & Not significant \\
\hline & 2 & 0.230 & Not significant \\
\hline & 3 & 0.126 & Not significant \\
\hline \multirow{3}{*}{$\begin{array}{l}\text { Weight shift in sagittal plane with closed eyes } \\
\text { (to the front-injury side) }\end{array}$} & 1 & 0.063 & Not significant \\
\hline & 2 & 0.265 & Not significant \\
\hline & 3 & 0.264 & Not significant \\
\hline \multirow{3}{*}{$\begin{array}{l}\text { Weight shift in sagittal plane with closed eyes } \\
\text { (to the back-injury side) }\end{array}$} & 1 & 0.07 & Not significant \\
\hline & 2 & 0.35 & Not significant \\
\hline & 3 & 0.096 & Not significant \\
\hline
\end{tabular}


Table 3. C statistic results of Biometrics Ltd E-LINK tests

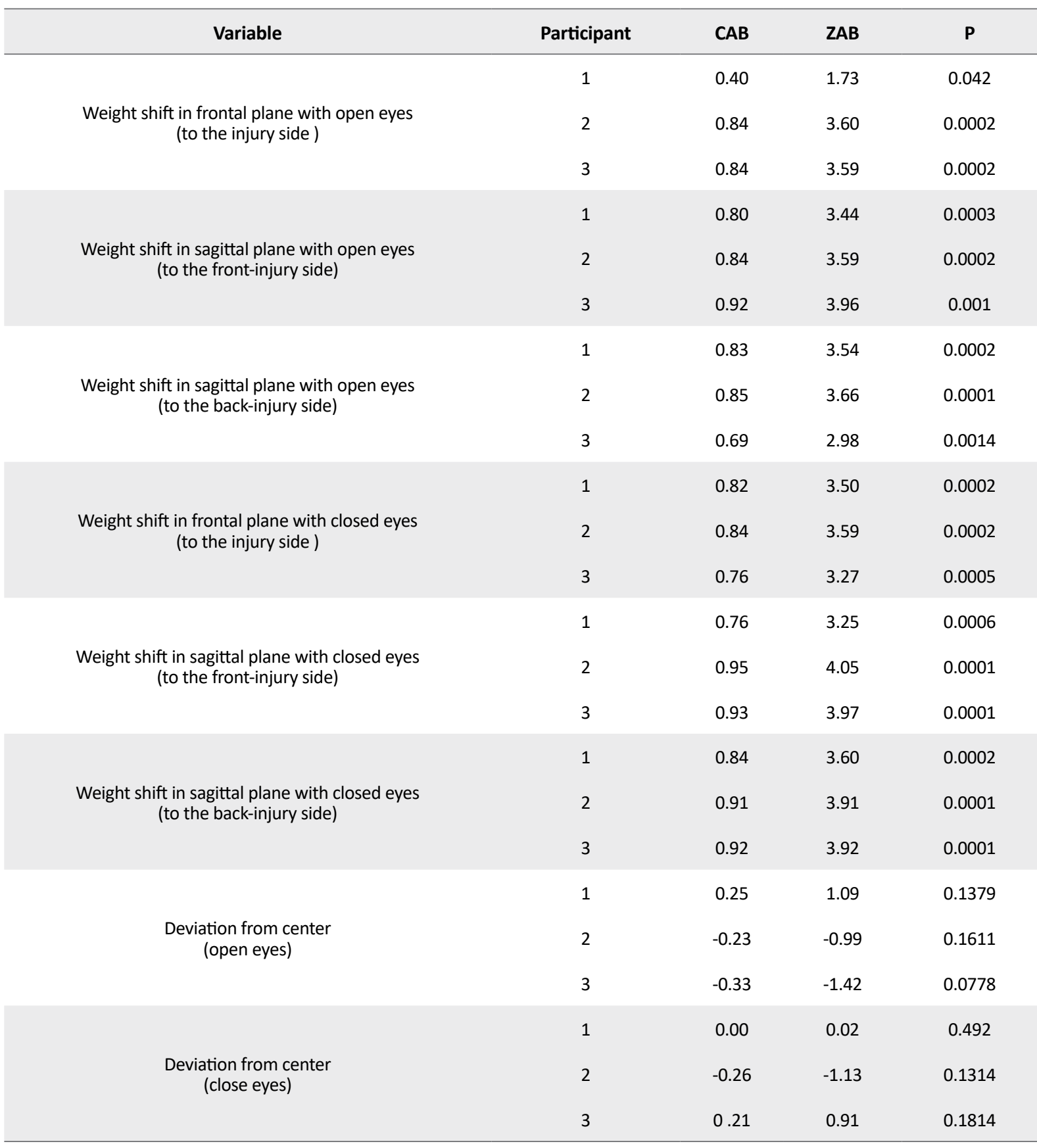

Iranian Rehabilitation Journal

Analysis of PRT data using C Static test, visual analysis, and 2SD method indicated significant changes from baseline phase to intervention phase $(\mathrm{P}<0.001)$ in all 3 directions in all patients. This analysis also suggested the stability of treatment effects in secondary evaluation phase. Analysis of Biometrics Ltd E-LINK data using C Static test, visual analysis, and 2SD method did not indicate significant changes in relation to the deviation from the center with open and closed eyes from baseline phase to intervention phase (Table 3).
Data analysis of the force plate device in the baseline phase and intervention phase using two-way ANOVA, except for calculating the velocity of the center of pressure in the direction of the sagittal plane $(\mathrm{P}=0.005)$, demonstrated no significant changes in any of the domains ( $\mathrm{P}=0.749$ for frontal plane, $\mathrm{P}=0.681$ for sagittal plane), velocity ( $\mathrm{P}=0.254$, for frontal plane), and the area of center of pressure $(\mathrm{P}=0.502)$ in closed and open eyes. 
Table 4. Results of single leg stance and activities scale for kids

\begin{tabular}{|c|c|c|c|c|c|}
\hline Variable & Participant & Baseline Phases & $\begin{array}{c}\text { Intervention Phases } \\
\left.\text { ( } 6^{\text {th }} \text { Session }\right)\end{array}$ & $\begin{array}{l}\text { Intervention Phases } \\
\left(12^{\text {th }} \text { session }\right)\end{array}$ & $\begin{array}{c}\text { Follow-up } \\
\text { Phases }\end{array}$ \\
\hline \multirow{3}{*}{$\begin{array}{c}\text { SLS } \\
\text { (Injury side) }\end{array}$} & 1 & $2.89 \mathrm{~s}$ & $7.85 \mathrm{~s}$ & $7 \mathrm{~s}$ & $4.33 \mathrm{~s}$ \\
\hline & 2 & $1 \mathrm{~s}$ & $1.78 \mathrm{~s}$ & $1.80 \mathrm{~s}$ & $1.06 \mathrm{~s}$ \\
\hline & 3 & $1.66 \mathrm{~s}$ & $1.47 \mathrm{~s}$ & $1.84 \mathrm{~s}$ & $1.50 \mathrm{~s}$ \\
\hline \multirow{3}{*}{ ASK } & 1 & 60 & 63.33 & 62.5 & 63.3 \\
\hline & 2 & 86.66 & 87.5 & 95 & 91.6 \\
\hline & 3 & 73.33 & 79.16 & 88.33 & 87.5 \\
\hline
\end{tabular}

In examining the post hoc test results, the fluctuation velocity of the center of pressure in the direction of the sagittal plane was significant only in comparison with the results of the second session $(\mathrm{P}=0.01)$. Moreover, the third phase of treatment $(\mathrm{P}=0.05)$ was significantly related to the results of secondary evaluation phase (Figure 4).

Results of ASK indicated performance improvement in participants from baseline phase to intervention phase (Table 4). Results of SLS did not suggest any changes in the single-leg stand ability in participants from baseline phase to intervention phase (Table 4).

\section{Discussion}

The current research was conducted to investigate the effect of implementing exercises using virtual reality on balance, postural control, and performance in children with CP as well as the stability of probable outcomes. In this study, dynamic balance variations were analyzed using the PRT. The maximum weight shift in the frontal and sagittal planes (with open and closed eyes) were calculated. The static balance changes were measured using the SLS. In addition, the velocity, domains, and the area of center of pressure in a static position (for 30 seconds) were examined on a force plate. Also, deviation from the center in a static position was measured using Biometrics Ltd E-LINK as a symmetric weight bearing device in standing position. Finally, the rate of patient's performance changes in daily activities was assessed using the ASK and parent's reports.

The dynamic balance test results revealed a significant improvement in the dynamic balance of patients in the intervention phase and higher stability of these changes in the secondary evaluation phase. This result is consistent

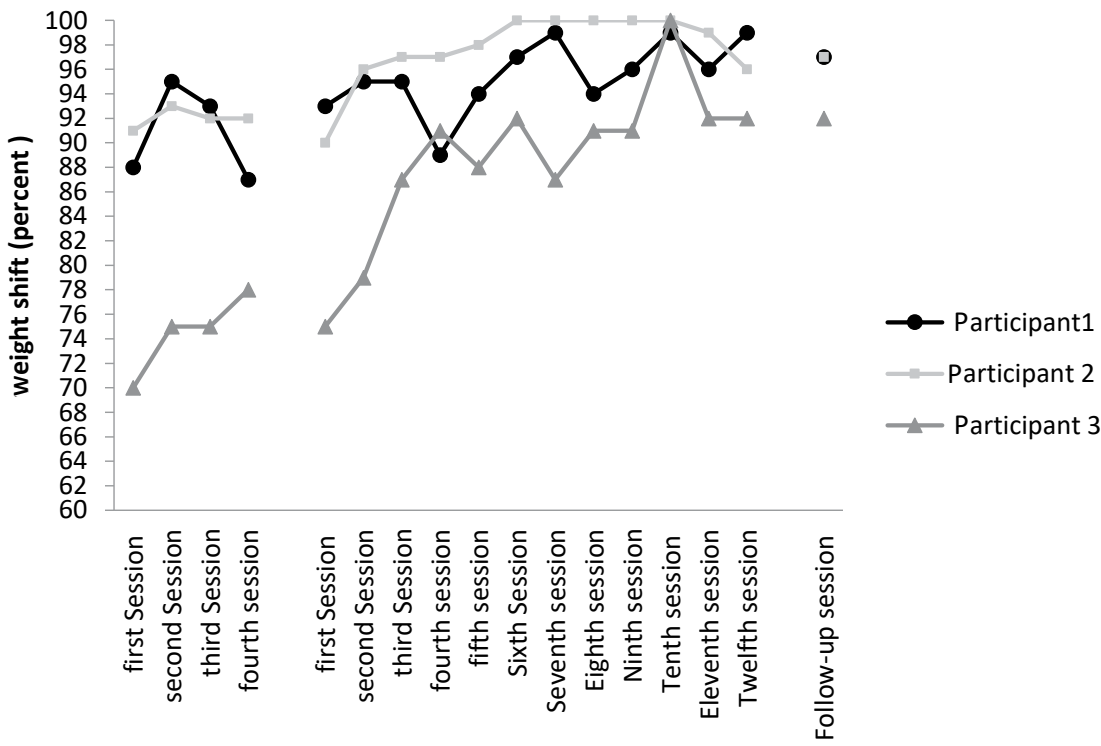

Figure 1. Weight shift in frontal plane with open eyes (to the injury side) 


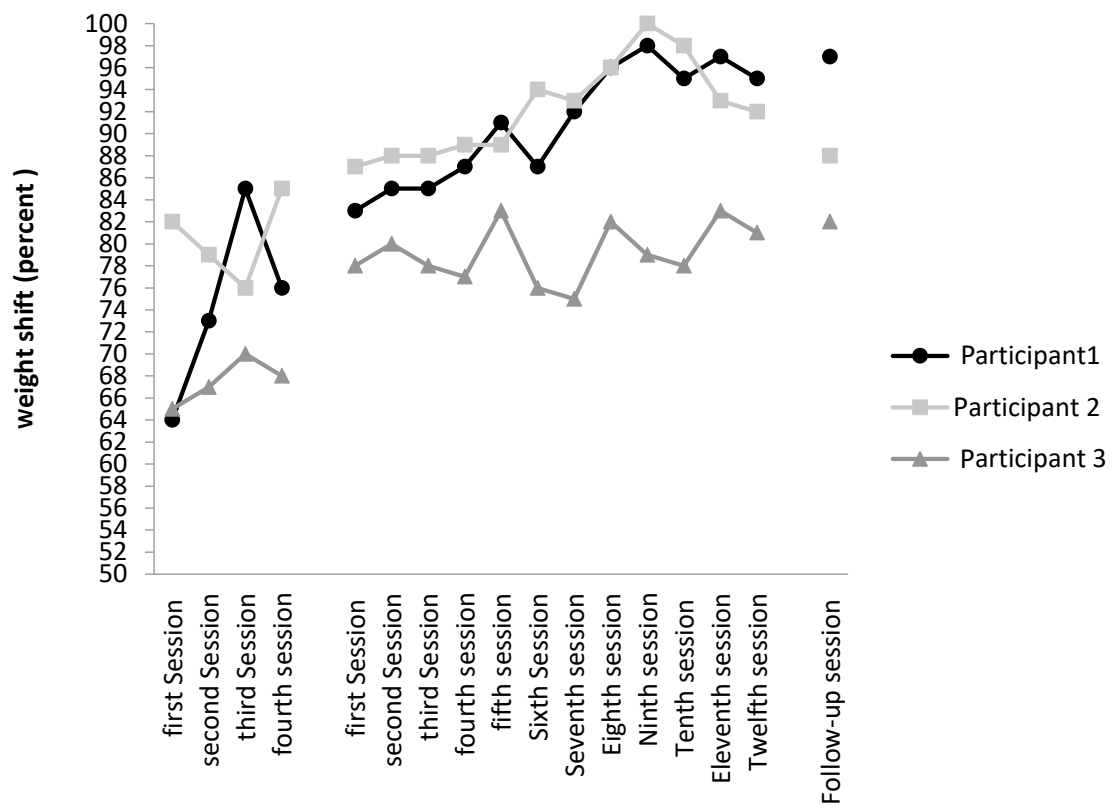

Figure 2. Weight shift in sagittal plane with open eyes (to the back-injury side)

Inranian Rehabilitation Journal

with findings by Brian [31], Deutsch [14], Luna-Oliva [32], Tarakci [33, 34], Jelsma [4], and Siconolfi-Morris [26]. We selected specialized exercises of weight shift in sagittal and frontal planes with varying speeds and forces and implemented them in the form of attractive computer games. This caused the higher participation of children in performing the exercises and repeating and enhancing ankle and pelvic balancing strategies. Thus, it was effective in improving the scores of dynamic balance in children. Thus, even 2-3 months after the com- pletion of intervention phase, stability of this treatment approach could have been observed.

However, the analysis of changes of patients in SLS, deviation from the center and reviewing the results on the force plate suggested no effect of the performed exercises on the improvement of children's static balance. Investigation of changes in the velocity of center of pressure of patients in sagittal plane also revealed no significant improvement from baseline to intervention phase. Only changes from the intervention to secondary evalu-

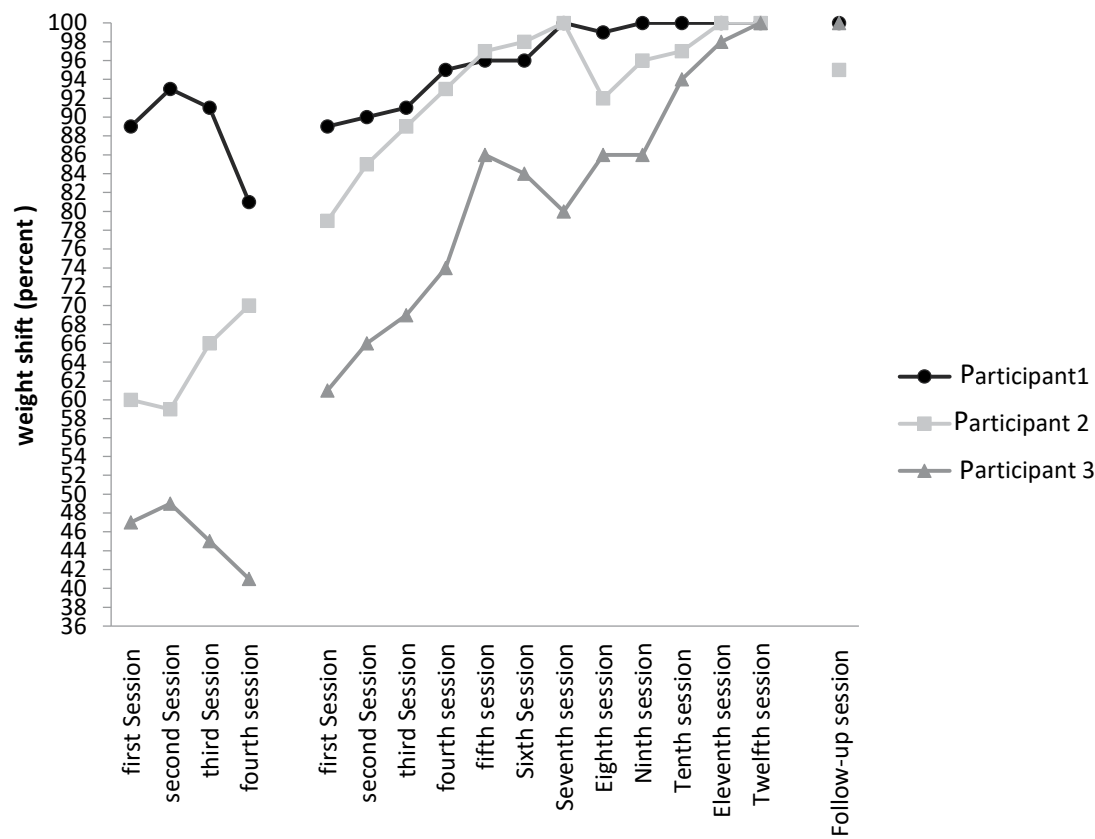

Figure 3. Weight shift to the front in injury side (sagittal plane-close eyes) 


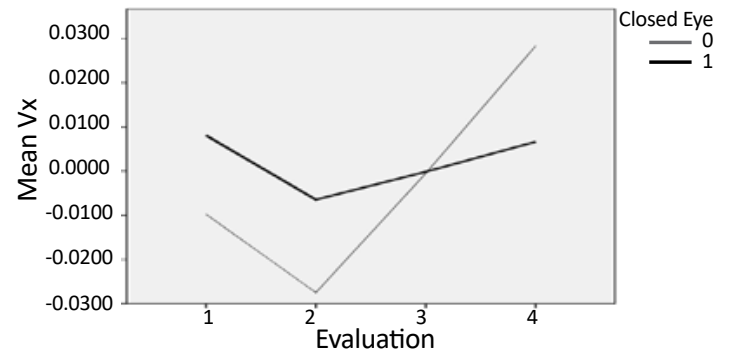

Iranian Rehabilitation Journal

Figure 4. Velocity of center of pressure in the sagittal plane (open eyes)

ation phase were interpreted as significant. Increased velocity of center of pressure and return to the baseline state were observed from the results and drawn graphs (according to the statistical investigation, the velocity of center of pressure difference in the primary and secondary evaluation phases was not significant).

In a similar study, Tatla also stated that implementing balance exercises using Nintendo Wii might improve dynamic balance in children with brain injury. However, it does not improve their static balance [20]. Ramstrand reported similar results as well. He found that a 5-week balance exercise program by Nintendo Wii had no impact on the velocity and the area of center of pressure [35]. Siconolfi-Morris (2012) studied children with CP and gained almost similar results. Siconolfi-Morris reported that the impact of 6 weeks of balance exercises by Nintendo Wii had trivial impact on velocity and the area of center of pressure of participants [26].

Unlike the current study, the work by Deutsch [14], Tarakci [33], Gatica-Rojas [36], and Brumels [9] demonstrated the positive impact of balance exercises by Nintendo Wii on reducing the fluctuations of center of pressure. The observed difference can be due to the focus of selected exercises on weight shift in sagittal and frontal planes. Furthermore, the selected exercises mostly challenged dynamic balance, and overlooked static balance, because the researcher assumed that weight shift practice also improves static balance [37]. However, the obtained results indicated that the improvement of dynamic balance could not be generalized to the static balance [19]. Therefore, the absence of appropriate exercises can explain such results. Moreover, differences among the participants and inconsistent studies should also be taken into account.

The current study was conducted on hemiplegic children with GMFCS level I. While in the study by Deutsch [14], a diplegic adolescent (GMFCS level III), in Tarakci [33] study a group study with different types of CP
(GMFCS levels I -III), and in Brumels [9] study healthy subjects with ankle injury were investigated. In addition, the number of sessions that children were treated using virtual reality should also be considered. Gatica-Rojas conducted 18 sessions with 3 repetitions per week [36]. Tarakci held 24 sessions twice a week [33]. In both studies, the number of practice sessions by patients using the virtual reality was more than the number of sessions in this study. Therefore, the difference between participants' diagnosis and the number of virtual reality treatment sessions could be considered effective in obtaining different outcomes. Subsequently, differences among participants also impact the results.

The improvement of children's independent performance in daily activities is the main goal of occupational therapy practices. However, ASK test results were considered as the secondary research objectives, because of the low odds of change in the results. ASK test results suggested the improvement of children performance in daily activities following 12 treatment sessions using Biometrics Ltd E-LINK. Siconolfi-Morris [26], LunaOliva [32], Tarakci [33], and Atasavun Uysal [38] indicated the positive impact of implementing balance exercises using computer systems on the independent performance of children with $\mathrm{CP}$.

The parents of children participating in this research reported the improvement of their children in performances not measured by ASK. The parent of Child 1 referred to the improved ability in wearing trousers and playing. The parent of Child 2 mentioned improved balance and tolerance of the child in long-term walking. The parent of Child 3 mentioned improvement in his ability to ride the bicycle, and balanced movement of both legs on the bicycle, as well as the increased speed of riding the bicycle. In the current study, consistent with the previous works, researcher believes the reason for such improvement is due to the impact of implementing and repeating different exercises, which are prerequisite for many daily activities. This refers to the positive impact of balance exercises on the performance capacity of individuals in performing daily activities.

Finally, in order to measure exercises enjoyment, the children's ideas and researcher's observations were considered. The tendency of children to do exercises revealed a decline from initial sessions to the ending sessions because of low variety of games and their simple graphics. However, all participants reported that this method of offering exercises is more enjoyable than the traditional approach, and they demanded to continue their treatment in this way. 


\section{Conclusion}

As previously stated, the ability to maintain balance and postural control is a key factor in various daily living activities. Therefore, it should be included in all rehabilitation programs. The results of this study suggested that weight shift practice using virtual reality did not improve static balance. However, it could improve the dynamic balance, and consequently increase the independent functioning of children in daily living activities. The obtained results also highlighted the need to incorporate both static and dynamic practices into children's balance rehabilitation programs. This is because selecting and performing dynamic balance practice may not be generalized to static balance. Furthermore, we observed the effect of virtual reality on encouraging children to therapeutic practices. Therefore, it seems that this technology, with its capabilities, can provide a variety of fun and meaningful therapeutic practices for clients and can serve as a useful tool in the rehabilitation of dynamic balance in hemiplegic CP children with characteristics identical to those in this research.

\section{Ethical Considerations}

\section{Compliance with ethical guidelines}

The present study was approved by the Ethics Committee of Iran University of Medical Sciences (code: 5532.D.105.93).

Funding

Current research was derived from a research proposal (research number: 25389) in Iran University of Medical Sciences.

\section{Authors contributions}

The authors contributions is as follows: Design, planning and writing: Afsoon Hassani Mehraban; and intervention, analysis and writing: Samira Boroumand.

\section{Conflict of interest}

The authors declared no conflict of interest.

\section{References}

[1] Krägeloh Mann I, Cans C. Cerebral palsy update. Brain and Development. 2009; 31(7):537-44. [DOI:10.1016/j.braindev.2009.03.009] [PMID]
[2] Kulak W, Sobaniec W. Comparisons of right and left hemiparetic cerebral palsy. Pediatric Neurology. 2004; 31(2):101-8. [DOI:10.1016/j.pediatrneurol.2004.01.009] [PMID]

[3] Cimolin V, Galli M, Tenore N, Albertini G, Crivellini M. Gait strategy of uninvolved limb in children with spastic hemiplegia. Europa Medicophysica. 2007; 43(3):303-10. [PMID]

[4] Jelsma J, Pronk M, Ferguson G, Jelsma Smit D. The effect of the Nintendo Wii Fit on balance control and gross motor function of children with spastic hemiplegic cerebral palsy. Developmental Neurorehabilitation. 2013; 16(1):27-37. [DOI: 10.3109/17518423.2012.711781] [PMID]

[5] Domagalska ME, Szopa AJ, Lembert DT. A descriptive analysis of abnormal postural patterns in children with hemiplegic cerebral palsy. Medical Science Monitor. 2011; 17(2):CR110CR6. [DOI:10.12659/MSM.881396] [PMID] [PMCID]

[6] Böhm H, Döderlein L. Gait asymmetries in children with cerebral palsy: Do they deteriorate with running? Gait \& Posture. 2012; 35(2):322-7. [DOI:10.1016/j.gaitpost.2011.10.003] [PMID]

[7] Radtka S, Hone R, Brown C, Mastick J, Melnick ME, Dowling GA. Feasibilityof computer-based videogame therapy for children with cerebral palsy. Games For Health. 2013 2(4):222-8. [DOI:10.1089/g4h.2012.0071] [PMID] [PMCID]

[8] Ledebt A, Becher J, Kapper J, Rozendaal RM, Bakker R, Leenders IC, et al. Balance training withvisual feedback in children with hemiplegic cerebral palsy: Effect on stance and gait. Motor Control. 2005; 9(4):459-68. [DOI:10.1123/ mcj.9.4.459] [PMID]

[9] Brumels KA, Blasius T, Cortright T, Oumedian D, Solberg B. Comparison of efficacy between traditional and video game based balance programs. Clinical Kinesiology. 2008; 62(4):26-32.

[10] Shumway Cook A, Woollacott MH. Motor control: Translating research into clinical practice. Philadelphia: Lippincott Williams \& Wilkins; 2007. [PMCID]

[11] Howcroft J, Klejman S, Fehlings D, Wright V, Zabjek K, Andrysek J, et al. Active video game play in children with cerebral palsy: Potential for physical activity promotion and rehabilitation therapies. Archives of Physical Medicine and Rehabilitation. 2012; 93(8):1448-56. [DOI:10.1016/j. apmr.2012.02.033] [PMID]

[12] Weiss PL, Rand D, Katz N, Kizony R. Video capture virtual reality as a flexible and effective rehabilitation tool. Journal of Neuroengineering and Rehabilitation. 2004; 1(1):12. [DOI:10.1186/1743-0003-1-12] [PMID] [PMCID]

[13] Rahman SA. Efficacy of virtual reality-based therapy on balance in children with Down syndrome. World Applied Sciences Journal. 2010; 10(3):254-61.

[14] Deutsch JE, Borbely M, Filler J, Huhn K, Guarrera Bowlby $\mathrm{P}$. Use of a low-cost, commercially available gaming console (Wii) for rehabilitation of an adolescent with cerebral palsy. Physical Therapy. 2008; 88(10):1196-207. [DOI:10.2522/ ptj.20080062] [PMID]

[15] Salem Y, Gropack SJ, Coffin D, Godwin EM. Effectiveness of a low-cost virtual reality system for children with developmental delay: A preliminary randomised single-blind controlled trial. Physiotherapy. 2012; 98(3):189-95. [DOI:10.1016/j. physio.2012.06.003] [PMID] 